\section{Prosocial Repertoire Mediates the Effects of Gratitude on Prosocial Behavior}

\author{
Ryuji Oguni $i^{1, *}$, Keiko Otake ${ }^{1,2}$ \\ 'Department of Psychological Science, Kwansei Gakuin University, 1-155, \\ Uegahara-1bancho, Nishinomiya, Hyogo, 662-8501, Japan \\ ${ }^{2}$ Center for Applied Psychological Science (CAPS), Kwansei Gakuin \\ University, 1-155, Uegahara-lbancho, Nishinomiya, Hyogo, 662-8501, \\ Japan \\ ‘Author for correspondence (ryuji.oguni@gmail.com)
}

Gratitude promotes prosocial behavior, but little is known about the psychological mechanisms that underpin this relationship. We examined whether the prosocial repertoire mediates the effects of gratitude on prosocial behavior. Participants were assigned to either a gratitude group or neutral group. We carried out emotion induction manipulation by recalling autobiographical memories and required participants to write prosocial repertoires they intended to do for others. One week later, participants had to report all the prosocial behaviors they engaged in during that period. The results indicated that the number of prosocial repertoires and prosocial behaviors in the gratitude group were higher than in the neutral group. Importantly, our results demonstrated that prosocial repertoires mediated the effects of gratitude on prosocial behavior. Our results suggest that prosocial repertoire is the crucial cognitive component involved in the relationship between gratitude and prosocial behavior.

\section{Keywords}

gratitude, prosocial behavior, thought-action repertoire, emotion induction

\section{Introduction}

Prosocial behavior provides us with a variety of benefits. Prosocial behavior is voluntary behavior intended to benefit another person (Eisenberg et al., 2006) and contributes to building and maintaining good relationships with others (Nowak \& Sigmund, 2005; Trivers, 1971). Moreover, although prosocial behavior come at a cost, they also improve one's own happiness (Aknin et al., 2013; Aknin et al., 2020; Dunn et al., 2008; Nelson et al., 2016; Otake et al., 2006). Empirical studies indicate that counting one's own prosocial behaviors (Otake et al., 2006) and spending money on others (Dunn et al., 2008) promote happiness. In this way, prosocial behavior is essential to the flourishing of our lives.

Gratitude is an important factor in promoting prosociality (for review, see Ma et al., 2017; Vaish \& Hepach, 2019). Gratitude is the positive emotion felt when one recognizes that another has given one value (McCullough, et al., 2001), and it promotes a variety of prosocial behaviors, such as helping (Bartlett \& DeSteno, 2006; Shoshani et al., 2020), sharing (Beeler-Duden \& Vaish, 2020; Chaplin et al., 2019; Shiraki \& Igarashi, 2018; Shoshani et al., 2020; Tsang, 2006, 2007; Tsang \& Martin, 2017), and cooperation (DeSteno et al., 2010). Bartlett and DeSteno (2006) experimentally examined the effects of gratitude on helping behavior. Participants were assigned to one of three groups: gratitude, amusement, and neutral. The gratitude group received help from a stranger, whereas the amusement group watched a humorous video clip with the stranger and the neutral group had a brief conversation with the stranger. The results revealed that participants in the gratitude group helped the stranger more than participants in the amusement and neutral groups. Interestingly, many studies have observed that gratitude promotes prosocial behavior toward not only the benefactor but also towards third parties (Bartlett \& DeSteno, 2006; Chaplin et al., 2019; DeSteno et al., 2010; Shiraki \& Igarashi, 2018; Shoshani et al., 2020). These findings demonstrate that gratitude plays an important role in promoting direct and upstream indirect reciprocity (Nowak \& Roch 2007; Nowak \& Sigmund, 2005; Trivers, 1971).

While there is strong evidence for the association between gratitude and prosocial behavior, it is still unclear what the underlying mechanism of this relationship is. The network model of emotion (Bower, 1981) represents individual emotion concepts as nodes. The individual nodes are connected to nodes of other concepts by links, and the distance between the nodes represents the semantic relatedness. When an emotion is evoked, the emotion node is activated and its activation is spread to other related nodes via links. Therefore, the network model of emotion expects that gratitude activate relatedbehaviors (e.g., helping, sharing) and - knowledge (e.g., norm of reciprocity) nodes. The broaden-and-build theory (Fredrickson, 1998, 2001) also supports these possibilities. This theory proposes that positive emotions widen thoughts that spontaneously come to mind and increase the likelihood of triggering a variety of behaviors. For example, positive emotions, relative to neutral and negative emotions, increase the thought-action repertoire (Fredrickson \& Branigan, 2005; Jäger \& Rüsseler, 2016). Moreover, Fredrickson $(2004,2013)$ suggests that the orientation of the thought-action repertoire corresponds to the characteristics of each positive emotion and gratitude increases the prosocial repertoire (e.g., "If I see a person in need, I would like to help them.") and the likelihood of providing widespread benefits to others. However, no studies have empirically examined whether gratitude promotes prosocial behavior through an increase in prosocial repertoire. To understand the cognitive processes 
involved in the relationship between gratitude and prosocial behavior, we investigated whether the prosocial repertoire mediates the effects of gratitude on prosocial behavior. We predicted that the influence of gratitude on prosocial behavior is mediated by the prosocial repertoire.

\section{Methods}

Participants and design

Sixty university students $\left(67 \%\right.$ females; $M_{\text {age }}=20.90$, $S D=0.99)$ were randomly assigned to the gratitude group $(N=30)$ and the neutral group $(N=30)$ betweensubjects design. Participants were received course credit for their participation. This study was approved by the Kwansei Gakuin University Institutional Review Board for Behavioral Research with Human Participants.

\section{Procedure}

We assessed participants' emotional states at the beginning of the experiment. Gratitude was assessed on a 5-point scale $(1=$ Not at all, $5=$ Extremely $)$, among other measures of emotion that are not discussed here. Afterwards, we asked them to recall an autobiographical memory: for the gratitude group, one where they felt gratitude and for the neutral group, their morning routines (e.g., tooth brushing and changing clothes). Both groups performed this task for five minutes. Then we measured their emotional states again. Next, participants wrote prosocial repertoires they wanted to do for others (e.g., "I would like to help people in need." "I would like to give up my seat to an elderly or pregnant woman." "I would like to donate money."). Approximately one week later, they reported what prosocial behaviors they did for others in the meantime (e.g., I helped my friends with their homework; I gave up my seat to the elderly; I donated money).

\section{Results}

Manipulation check of gratitude

We calculated the difference score of gratitude subtracting pre- from post-manipulation in both groups. A BrunnerMunzel test indicated that the scores in the gratitude group
$(M=1.47, S D=1.53)$ were significantly higher than in the neutral group $(M=-0.23, S D=0.94), t(42.36)=5.84, p<$ $.01, r=.55$.

\section{Effects of gratitude on prosocial repertoire and prosocial behavior}

Figure 1 and table 1 indicates the number of prosocial repertoires and prosocial behaviors for each group. A Brunner-Munzel test revealed that the number of reported prosocial repertoires and prosocial behaviors in the gratitude group were higher than in the neutral group, $t$ $(54.66)=5.72, p<.01, r=.54, t(55.59)=5.21, p<.01, r=$ .51 , respectively.

Table 1. Mean number of reported prosocial repertoires and behaviors and standard errors for the gratitude and neutral groups.

\begin{tabular}{cccccc}
\hline & \multicolumn{2}{c}{ Prosocial repertoire } & & \multicolumn{2}{c}{ Prosocial behavior } \\
\cline { 2 - 3 } \cline { 5 - 6 } & Mean & $S E$ & & Mean & $S E$ \\
\hline Gratitude & 5.07 & 0.26 & & 4.53 & 0.39 \\
\hline Neutral & 3.40 & 0.22 & & 2.63 & 0.21 \\
\hline
\end{tabular}

Prosocial repertoire mediates the effects of gratitude on prosocial behavior

To examine whether the influence of gratitude on prosocial behavior is mediated by the prosocial repertoire, mediation analysis was conducted using the bootstrapping method (10,000 samples; Fig. 2). First, we found that the group $(1=$ gratitude, $0=$ neutral) was positively associated prosocial behavior $(\beta=.49, p<.01)$. Then, the prosocial repertoire was entered as a mediating variable. As results, the group was positively associated prosocial repertoire $(\beta=.54, p$ $<.01)$ and prosocial repertoire was positively associated prosocial behavior $(\beta=.29, p=.03)$. The direct effect of the group on prosocial behavior remained significant $(\beta$ $=.33, p=.02)$. These results indicated that the prosocial repertoire partially mediates the effects of gratitude on prosocial behavior $(95 \%$ Confidence Interval $=[0.01$, $1.56])$.
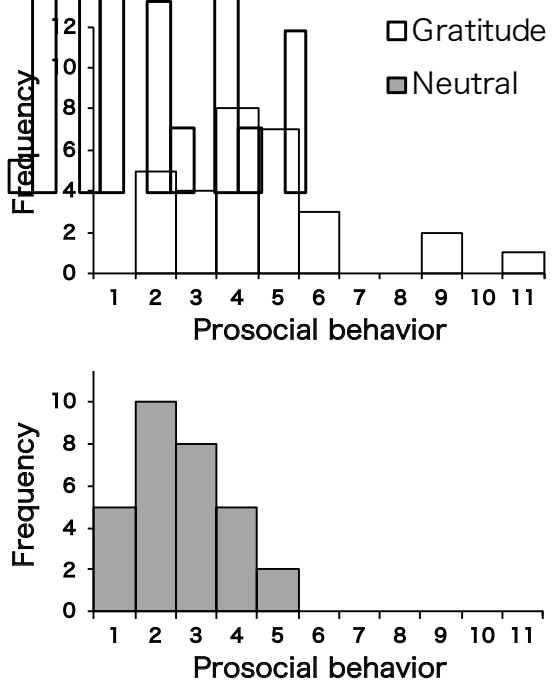

Figure 1. The histogram of prosocial repertoires and behaviors for the gratitude and neutral groups. 


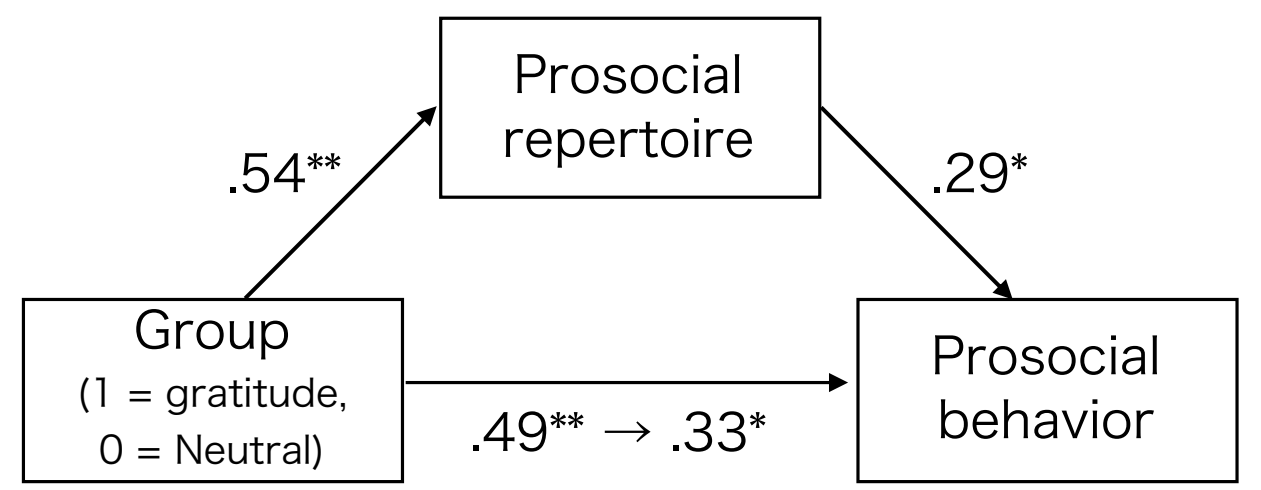

Figure 2. The mediating role of prosocial repertoires in the effect of gratitude on prosocial behavior.

Note. Standardized coefficients are reported; $* *=p<.01, *=p<.05$

\section{Discussion}

We examined whether gratitude promotes prosocial behavior through prosocial repertoires. We carried out emotion induction manipulation and measured prosocial repertoires and prosocial behaviors. The results showed that gratitude increased prosocial repertoires and prosocial behavior. Importantly, we found that prosocial repertoires mediate the effect of gratitude on prosocial behavior. Therefore, the results of this study suggest that prosocial repertoire is the crucial cognitive component through which gratitude promotes prosocial behavior.

The broaden-and-build theory proposes that positive emotions increase the thought-action repertoire and the likelihood of triggering a variety of behaviors (e.g., Fredrickson, 2001). Fredrickson $(2004,2013)$ suggested that characteristics of each positive emotion correspond to the orientation of the thought-action repertoire and that gratitude increases the prosocial repertoire. However, the relationship between discrete positive emotions and thought-action repertoire have not been fully explored. Our results empirically support Fredrickson's (2004, 2013) claim and suggest that the characteristics of individual positive emotions determine the orientation of the thoughtaction repertoire. Furthermore, understanding our results in the framework of the network model of emotion (Bower, 1981) provides useful implications. This model explains that when an emotion is evoked, the activation spreads to nodes associated with the emotion node. Accordingly, gratitude activates related-behaviors and -knowledge nodes, hence increasing prosocial repertoires. The network model of emotion could be also one of the frameworks that can explain why the effects vary by discrete positive emotions.

Here, we examined the role of prosocial repertoires play in the gratitude - prosocial behavior relationship, but more research is needed into other factors with similar effects. First, comparisons with other social emotions help confirm the specific function of gratitude. In the gratitude group, participants recalled episodes in which they interacted with others, which may have created more repertoire related to others. Although previous studies on the prosocial function of gratitude have also only compared gratitude with nonsocial emotions (e.g., Bartlett \& DeSteno, 2006), it is important that future research rigorously examine whether the results of this study are replicated by comparing gratitude with other social emotions (e.g., awe, pride). Second, other processes involved in the relationship between gratitude and prosocial behavior also need to be understood. Our results indicated the effect of gratitude on prosocial behavior was only partially mediated by prosocial repertoires. This suggests that there are other significant processes to promote prosocial behaviors. For example, McCullough et al. (2001) pointed out that motivational processes exist in the background in which gratitude promotes prosocial behavior. Similarly, the effects of gratitude on prosocial behavior were mediated by the motivation to connect with others (Shiraki \& Igarashi, 2018); thus, even if gratitude increased the prosocial repertoire, prosocial behavior would not be promoted when the motivation for those behaviors was low. Hence, gratitude likely elicits other psychological processes aside from prosocial repertoires as well and further investigation is needed.

In conclusion, we provided empirical evidence supporting the hypothesis that prosocial repertoires mediate the effect of gratitude on prosocial behavior. We expect that these findings will lead to further elucidation of the psychological process by which gratitude promotes prosocial behavior.

\section{Acknowledgement}

This work was supported in part by JSPS KAKENHI Grant No. 15K04165 and No. JP19H01766. The experiment was conducted as a part of the project supported by the Ministry of Education, Culture, Sports, Science and Technology (MEXT), JAPAN, for the Strategic Research Foundation at Private Universities (2015-2019; Project No. S1511032) to the Center for Applied Psychological Science (CAPS), Kwansei Gakuin University.

\section{References}

Aknin, L. B., Barrington-Leigh, C. P., Dunn, E. W., Helliwell, J. F., Burns, J., Biswas-Diener, R., Kemeza, I., Nyende, P., Ashton-James, C. E., \& Norton, M. I. (2013). Prosocial spending and well-being: Crosscultural evidence for a psychological universal. Journal of Personality and Social Psychology, 104, 635-652. https://doi.org/10.1037/a0031578

Aknin, L. B., Dunn, E. W., Proulx, J., Lok, I., \& Norton, M. I. (2020). Does spending money on others promote happiness?: A registered replication report. Journal 
of Personality and Social Psychology, 119, e15-e26. https://doi.org/10.1037/pspa0000191

Bartlett, M. Y., \& DeSteno, D. (2006). Gratitude and prosocial behavior: Helping when it costs you. Psychological Science, 17, 319-325. https://doi. org/10.1111/j.1467-9280.2006.01705.x

Beeler-Duden, S., \& Vaish, A. (2020). Paying it forward: The development and underlying mechanisms of upstream reciprocity. Journal of Experimental Child Psychology, 192, 104785. https://doi.org/10.1016/ j.jecp.2019.104785

Bower, G. H. (1981). Mood and memory. American Psychologist, 36,129-148. https://doi. org/10.1037/0003-066X.36.2.129

Chaplin, L. N., John, D. R., Rindfleisch, A., \& Froh, J. J. (2019). The impact of gratitude on adolescent materialism and generosity. The Journal of Positive Psychology, 14, 502-511. https://doi.org/10.1080/17439 760.2018 .1497688

DeSteno, D., Bartlett, M. Y., Baumann, J., Williams, L. A., \& Dickens, L. (2010). Gratitude as moral sentiment: Emotion-guided cooperation in economic exchange. Emotion, 10, 289-293. https://doi.org/10.1037/a0017883

Dunn, E. W., Aknin, L. B., \& Norton, M. I. (2008). Spending money on others promotes happiness. Science, 319, 1687-1688. https://doi.org/10.1126/ science. 1150952

Eisenberg, N., Fabes, R. A., \& Spinrad, T. L. (2006). Prosocial development. In N. Eisenberg, W. Damonand, \& R. M. Lerner (Eds.), Handbook of child psychology, Vol. 3: Social, emotional, and personality development (6th ed., pp. 646-718). John Wiley. https://doi.org/10.1002/9780470147658.chpsy0311

Fredrickson, B. L. (1998). What good are positive emotions? Review of General Psychology, 2, 300-319. https://doi.org/10.1037/1089-2680.2.3.300

Fredrickson, B. L. (2001). The role of positive emotions in positive psychology: The broaden-and-build theory of positive emotions. American Psychologist, 56, 218226. https://doi.org/10.1037/0003-066X.56.3.218

Fredrickson, B. L. (2004). Gratitude, like other positive emotions, broadens and builds. In R. A. Emmons, \& M. E. McCullough (Eds.), The Psychology of Gratitude (pp. 145-166). Oxford University Press.

Fredrickson, B. L. (2013). Positive emotions broaden and build. Advances on Experimental Social Psychology, 47, 1-53. https://doi.org/10.1016/B978-0-12-4072367.00001-2

Fredrickson, B. L., \& Branigan, C. (2005). Positive emotions broaden the scope of attention and thoughtaction repertoires. Cognition \& Emotion, 19, 313-332. https://doi.org/10.1080/02699930441000238

Jäger, D. T., \& Rüsseler, J. (2016). Low arousing positive affect broadens visual attention and alters the thoughtaction repertoire while broadened visual attention does not. Frontiers in Psychology, 7, 1652. https://doi. org/10.3389/fpsyg.2016.01652

Ma, L. K., Tunney, R. J., \& Ferguson, E. (2017). Does gratitude enhance prosociality?: A meta-analytic review. Psychological Bulletin, 143, 601-635. https:// doi.org/10.1037/bu10000103

McCullough, M. E., Kilpatrick, S. D., Emmons, R. A., \& Larson, D. B. (2001). Is gratitude a moral affect? Psychological Bulletin, 127, 249-266. https://doi. org/10.1037/0033-2909.127.2.249

Nelson, S. K., Layous, K., Cole, S. W., \& Lyubomirsky, S. (2016). Do unto others or treat yourself? The effects of prosocial and self-focused behavior on psychological flourishing. Emotion, 16, 850-861. https://doi. org/10.1037/emo0000178

Nowak, M. A., \& Roch, S. (2007). Upstream reciprocity and the evolution of gratitude. Proceedings of the Royal Society B: Biological Sciences, 274, 605-610. https://doi.org/10.1098/rspb.2006.0125

Nowak, M. A., \& Sigmund, K. (2005). Evolution of indirect reciprocity. Nature, 437, 1291-1298. https:// doi.org/10.1038/nature04131

Otake, K., Shimai, S., Tanaka-Matsumi, J., Otsui, K., \& Fredrickson, B. L. (2006). Happy people become happier through kindness: A counting kindnesses intervention. Journal of Happiness Studies, 7, 361-375. https://doi.org/10.1007/s10902-005-3650-z

Shiraki, Y., \& Igarashi, T. (2018). "Paying it forward" via satisfying a basic human need: The need for relatedness satisfaction mediates gratitude and prosocial behavior. Asian Journal of Social Psychology, 21, 107-113. https://doi.org/10.1111/ ajsp.12211

Shoshani, A., De-Leon Lendner, K., Nissensohn, A., Lazarovich, G., \& Aharon-Dvir, O. (2020). Grateful and kind: The prosocial function of gratitude in young children's relationships. Developmental Psychology, 56, 1135-1148. https://doi.org/10.1037/dev0000922

Trivers, R. L. (1971). The evolution of reciprocal altruism. The Quarterly Review of Biology, 46, 35-57. https:// doi.org/10.1086/406755

Tsang, J. A. (2006). Gratitude and prosocial behaviour: An experimental test of gratitude. Cognition and Emotion, 20, 138-148. https://doi. org $/ 10.1080 / 02699930500172341$

Tsang, J. A. (2007). Gratitude for small and large favors: A behavioral test. The Journal of Positive Psychology, 2 , 157-167. https://doi.org/10.1080/17439760701229019

Tsang, J. A., \& Martin, S. R. (2017). Four experiments on the relational dynamics and prosocial consequences of gratitude. The Journal of Positive Psychology, 14, 188205. https://doi.org/10.1080/17439760.2017.1388435

Vaish, A., \& Hepach, R. (2019). The development of prosocial emotions. Emotion Review. https://doi. org/10.1177/1754073919885014. 